\title{
Probiotics for Prosperity: Is There a Role for Probiotics in the Fight Against Obesity? Review of Meta-Analyses of Randomized Controlled Trials
}

\author{
Elena Barengolts ${ }^{1,2}$ \\ Michael Salim (D) ${ }^{3}$ \\ Arfana Akbar ${ }^{2}$ \\ Farah Salim ${ }^{2}$
}

'Division of Endocrinology, Diabetes, and Metabolism, Department of Medicine, University of Illinois, Chicago, IL 606I2, USA; ${ }^{2}$ Section of Endocrinology,

Department of Medicine, Jesse Brown VA Medical Center, Chicago, IL 606I2, USA; ${ }^{3}$ Department of Internal Medicine, Mount Sinai Hospital, Chicago, IL 60608, USA
This article was published in the following Dove Press journal: Nutrition and Dietary Supplements

Purpose: Obesity is a chronic disease that is acquiring pandemic proportions. Emerging research suggests that probiotics can be a valuable yet still an underutilized modality for obesity treatment. This review aims to analyze and summarize recent data focusing on published meta-analyses of randomized controlled trials (RCTs) to help understand the role of probiotics in fighting obesity.

Materials and Methods: Meta-analyses were sought and reviewed from PubMed, Cochrane Central Library, ScienceDirect, and Google Scholar for body weight and/or BMI changes (two main outcomes of interest).

Results: The literature review identified 14 meta-analyses. On average, the meta-analyses dedicated to probiotics included 4-15 trials with 154-994 participants, whereas more inclusive probiotics and/or synbiotics analyses included 15-68 trials with 895-4015 participants. Eleven out of 14 meta-analyses showed that probiotic use in RCTs resulted in reduced body weight and/or BMI compared to placebo. An average weight loss was $0.6 \mathrm{~kg}$, and the most substantial loss was $4.8 \mathrm{~kg}$ corresponding to $0.7 \%$ and $5.9 \%$ reductions in body weight, respectively. Probiotics' use was associated with improved health outcomes in addition to weight loss and was safe. The subgroup analyses showed that the probiotic forms (supplements vs food) and the dosages (lower vs higher than $10^{10} \mathrm{CFU} /$ day) did not substantially influence weight loss. The single species particularly helpful for weight loss appeared to be L. gasseri, L. casei, L. delbrueckii, L. reuteri, L. rhamnosus, a combination of L. curvatus and L. plantarum and Bifidobacterium longum. Bacillus subtilis and Akkermansia muciniphila also had a potential as anti-obesity probiotics.

Conclusion: Probiotics, despite small effects, could be a valuable addition to the armamentarium of obesity management. Further basic and translational research and clinical trials are required to elucidate mechanisms and specific probiotic and patients' types for the best achievable precision medicine approach to the obesity epidemic.

Keywords: probiotic, synbiotic, obesity, overweight, body weight, body mass index

\section{Introduction}

Obesity is a chronic disease that is acquiring pandemic proportions. The last available data estimate that approximately one of eight adults is obese, and almost 1 of 2 is overweight. Overall, about 13\% (650 million) of the world's adult population (11\% of men and $15 \%$ of women) were obese. ${ }^{1}$ About $40 \%$ (1.9 billion) were overweight in 2016. ${ }^{1,2}$ The categories of overweight and obesity are based on measuring body weight (BW) and height and calculating body mass index (BMI) as $\mathrm{kg} / \mathrm{m}^{2}$. The designations
Correspondence: Elena Barengolts Section of Endocrinology, Department of Medicine, Jesse Brown VA Medical Center, Chicago, IL 606I2, USA

Tel $+|-3| 2-996-6060$

Fax + I-3|2-569-8|23

Email eibareng@uic.edu 
for normal and abnormal weight using standard BMI $\left(\mathrm{kg} / \mathrm{m}^{2}\right)$ categories are as follows: normal 18.5-24, overweight 25-29, obesity grade-1 30-34, grade-2 35-39, and grade$3 \geq 40$. $^{3}$

The Obesity Society (TOS) defines obesity as "a multicausal chronic disease ... associated with premature mortality". 4 Most of the excess mortality is due to cardiovascular disease (mainly heart disease and stroke) and some cancers (particularly common cancers, breast, and colon). ${ }^{1}$ The cardiovascular mortality was almost twofold higher in severely obese $(\mathrm{BMI} \geq 35)$ than normal-weight individuals in a meta-analysis of prospective cohort studies comprising more than 250,000 participants followed for about 4 years. ${ }^{5}$ The breast cancer mortality was increased by about $75 \%$ and $35 \%$ for pre- and post-menopausal obese (BMI $>30$ before the diagnosis) compared to normal-weight women, respectively, based on a meta-analysis of more than 200,000 women. $^{6}$ The colorectal cancer all-cause and cancerspecific mortality were both increased by about $15 \%$ based on the pooled data for more than 50,000 participants followed for about 10 years. ${ }^{7}$ The meta-analysis of prospective studies comprising 2.9 million individuals and more than 270,000 deaths, showed that severe obesity (BMI $\geq 35)$ was associated with about $30 \%$ increased overall (all-cause) mortality. ${ }^{8}$ Multiple conditions could be called complications of obesity and could be mitigated at least in part by weight loss. These include type 2 diabetes (T2D), hypertension (HTN), metabolic syndrome (MetS), non-alcoholic fatty liver disease (NAFLD), heart failure, obstructive sleep apnea, chronic kidney disease, infections and arthritis. ${ }^{1}$ Obesity places a high psychological and economic burden on the individual patient, healthcare system and society. ${ }^{1,4}$

Management of obesity requires a multidisciplinary and multifactorial approach. According to the Guidelines from the Obesity and other societies: "To achieve weight loss, an energy deficit is required". 9 The safest approach to achieve energy deficit is lifestyle modification that, however, is difficult to change. ${ }^{10}$ Anti-obesity medications usage is also difficult due to poor adherence, side effects, and high cost. ${ }^{11,12}$ Anti-obesity surgery is the most efficacious treatment for weight loss yet has its own limitations and high cost. ${ }^{13}$

Emerging research suggests that gut microbiota have a critical role in obesity. ${ }^{14-16}$ Microbiota could increase ${ }^{14}$ or decrease ${ }^{17}$ the harvest of energy from the utilization of food, ${ }^{18}$ lower appetite, increase satiety, ${ }^{19}$ and influence multiple conditions. ${ }^{20}$ Modification of the gut microbiota can be achieved with probiotics, potential yet still an underutilized mode of obesity treatment. ${ }^{20-22}$ Probiotics are defined as "live microorganisms that, when administered in adequate amounts, confer a health benefit on the host." 21 Probiotics could be combined with prebiotics; a combination called synbiotics. Prebiotic is "a substrate that is selectively utilized by host microorganisms conferring a health benefit." The majority of prebiotics are dietary fibers that can promote probiotics' survival in the gut. $^{23}$ In the USA, about $\$ 400$ million has been spent on probiotic supplements in 2019 and spending is projected to grow to about 2.5 billion by $2024 .^{24}$ Numerous studies suggest that probiotics could help weight loss. $^{20-22}$ However, the gap of knowledge remains since probiotic supplementation can promote both weight loss and weight gain. ${ }^{25}$ This review aims to analyze and summarize recent data focusing on published meta-analyses of randomized controlled trials (RCTs) to help understand whether there is a role for probiotics in the fight against obesity.

\section{Materials and Methods}

Meta-analyses were sought and retrieved from electronic databases. The search engines included PubMed/MEDLINE (http://www.ncbi.nlm.nih.gov/pubmed), Cochrane Central library (https://www.cochranelibrary.com), ScienceDirect (https://www.sciencedirect.com), and Google Scholar (https://scholar.google.com). A combination of the following keywords was used: overweight, obesity, probiotic, synbiotic, yogurt, Lactococcus, Lactobacillus, Bifidobacterium, Streptococcus, weight change, weight modification, weight regulation, weight loss, weight reduction, weight management, treatment, meta-analysis. The logical connectives AND, OR, and NOT were systematically used to combine terms used to identify articles with search strings identified in Table S1. Filters were applied in order to limit the searches to meta-analyses. Studies reporting either body weight or body mass index (two main outcomes of interest) were included in this review. Studies dedicated to children, animals, and some conditions (eg, pregnancy, fatty liver disease, PCOS) were excluded. The literature search was consistent with Preferred Reporting Items for Systematic Reviews and Meta-Analysis (PRISMA) (Figure 1).

Articles published in English from January 1, 2000, until July 10, 2020, were retrieved and reviewed. Two researchers (BE and $\mathrm{SM}$ ) conducted the selection of the articles. The final selection of the papers was determined through discussions and agreement of the researchers. Of 


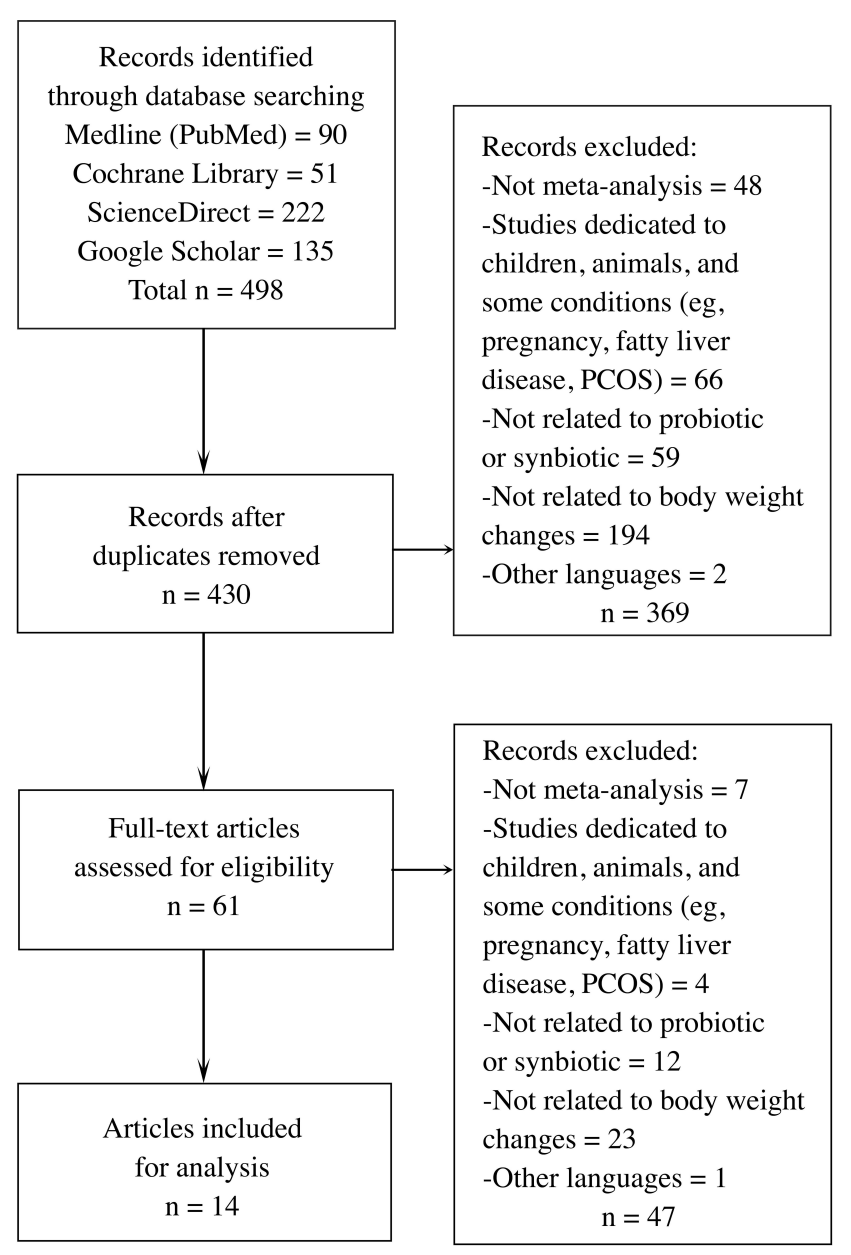

Figure I PRISMA flow diagram for study selection.

Notes: PRISMA figure adapted from Liberati A, Altman D, Tetzlaff Jet al The PRISMA statement for reporting systematic reviews and meta-analyses of studies that evaluate health-care interventions: explanation and elaboration. Journal of Clinical Epidemiology. 2009; 62(10). Creative Commons.

the 498 papers extracted by the search strategy, 14 articles met the eligibility criteria and were reviewed in detail.

\section{Results}

The literature review identified 14 meta-analyses dedicated to evaluating probiotic and/or synbiotic effects on body weight and/or BMI (Table 1). ${ }^{26-39}$ Overall, the majority (11 of 14) of meta-analyses showed that probiotic use in RCTs resulted in reduced body weight and/or BMI compared to placebo. $^{26-28,30-33,35,36,38,39}$ Similarly, most of the analyses showed a reduction of other anthropometric measures, including waist circumference, body fat mass, and/or body fat percentage. ${ }^{26-29,31-33,35-38}$ Meta-analyses that included metabolic and inflammation-related parameters predominantly showed beneficial effects for those measures. The improvements were demonstrated for glucose, ${ }^{28,33,38} \mathrm{HbA1c},{ }^{28,33}$ insulin, ${ }^{28,33,38}$ HOMA-
IR, ${ }^{28,33,38}$ lipids, ${ }^{28,29,36,38}$ liver function test, ${ }^{33}$ and inflammatory markers. ${ }^{36}$ Table 1 shows the main outcomes (body weight and BMI), additional anthropometric outcomes (waist circumference and body fat), and relevant subgroup analyses. A detailed description of meta-analyses and outcomes is provided in Tables S2 and S3. There were 9, 4, and 5 reports that separately evaluated probiotics, synbiotics, and combination of pro- with synbiotics, respectively. The meta-analyses were published between 2015 and 2020 and predominantly were similar in the inclusion and exclusion criteria for RCTs (Table S2). On average, the meta-analyses dedicated to probiotics included 4-15 trials with 154-994 participants, whereas more inclusive probiotics and/or synbiotics analyses included 15-68 trials with 895-4015 participants. The majority of RCTs included in meta-analyses were blinded or open parallel-group trials, conducted between 1990 and 2019 in a single-center, with the duration of 2-28 (median 8) weeks, and included two groups, intervention, and placebo, with some trials including more than two and up to five groups. The cross-over RCTs were included if they reported outcomes at the end of the first cross-over period. The main exclusion was insufficient data and/or incomplete information, though the definition of incompleteness could vary among meta-analyses. Some meta-analyses only included RCTs providing details for mean and standard deviations for the selected outcomes; however, the preponderance of meta-analyses calculated these parameters if these were missing. ${ }^{34}$

The participants of RCTs were predominantly overweight or obese (a few included normal weight) adults of both genders (some included only women), with or without comorbidities, and some were dedicated to specific populations (eg, metabolic syndrome). About a third of RCTs included patients with comorbidities such as T2D, NAFLD, metabolic syndrome, and hypertension. Some included patients prior to or after Roux-en-Y gastric bypass (RYGB). ${ }^{33}$ The majority of intervention groups were taking probiotics in capsule or powder form (about two-thirds of RCTs) rather than food (yogurt, fermented milk, kefir, cheese). In contrast, control groups used nonactive comparators (placebo), that is, products that contained no probiotics or synbiotics. The probiotic key components were the following genera: Bifidobacterium, Lactobacillus, Lactococcus, Leuconostoc, Oenococcus, Pediococcus, Propionibacterium and Streptococcus with the doses varying from $10^{6}$ to $10^{12}$ colony forming units (CFU) per day. Some meta-analyses excluded RCTs in which the probiotic bacteria were not defined to the level 
Table I Meta-Analyses of Trials Including Probiotics and/or Synbiotics Use for Obesity

\begin{tabular}{|c|c|c|c|c|c|c|}
\hline $\begin{array}{l}\text { Study } \\
\text { Author, Year }\end{array}$ & $\begin{array}{l}\text { N } \\
\text { BW } \\
\text { BMI }\end{array}$ & $\begin{array}{l}\text { n } \\
\text { BW } \\
\text { BMI }\end{array}$ & $\begin{array}{l}\text { Dur } \\
\text { wks }\end{array}$ & $\begin{array}{l}\text { Base } \\
\text { BW } \\
\text { BMI }\end{array}$ & $\begin{array}{l}\text { Mean Difference } \\
\text { BW }(95 \% \mathrm{Cl}) \\
\text { BMI }(95 \% \mathrm{Cl})\end{array}$ & $\begin{array}{l}\text { Additional Anthropometric Outcomes, Subgroup and } \\
\text { Regression Analysis, and Comments. }\end{array}$ \\
\hline $\begin{array}{l}\text { Borgeraas } \\
\text { et al, } 2018^{26}\end{array}$ & $\begin{array}{l}777 \\
866\end{array}$ & 13 & $3-12$ & $\begin{array}{l}81 \\
28\end{array}$ & $\begin{array}{l}-0.60(-1.19,-0.01) \\
-0.27(-0.45,-0.08)\end{array}$ & $\begin{array}{l}\text { BFM: }-0.42(-1.08,0.23) \\
\text { BF }(\%):-0.60(-1.20,-0.01) \\
\text { Subgroup analysis: larger effect in generally healthy, duration >8 (vs } \\
<8) \text { wks, food (vs capsules), if BW was the primary outcome. }\end{array}$ \\
\hline $\begin{array}{l}\text { Cao et al, } \\
2020^{27}\end{array}$ & $\begin{array}{l}\text { NR } \\
2105\end{array}$ & $\begin{array}{l}\text { NR } \\
32\end{array}$ & $3-12$ & $\begin{array}{l}\text { NR } \\
\text { NR }\end{array}$ & $\begin{array}{l}\text { NR } \\
-0.25(-0.33,-0.17)\end{array}$ & $\begin{array}{l}\text { WC: }-0.99(-1.33,-0.66) \\
\text { BF }(\%):-0.75(-0.90,-0.6 \mathrm{I}) \\
\text { Regression analysis: inverse association between duration and weight } \\
\text { loss. }\end{array}$ \\
\hline $\begin{array}{l}\text { Companys } \\
\text { et al, } 2020^{28}\end{array}$ & $\begin{array}{l}666 \\
840\end{array}$ & $\begin{array}{l}10 \\
12\end{array}$ & $4-24$ & $\begin{array}{l}\text { NR } \\
\text { NR }\end{array}$ & $\begin{array}{l}-0.26(-0.43,-0.09)^{\mathrm{a}} \\
-0.35(-0.48,-0.22)^{\mathrm{a}}\end{array}$ & $\begin{array}{l}\text { WC: }-0.37(-0.52,-0.21)^{\mathrm{a}} \\
\text { BFM: }-0.30(-0.48,-0.12)^{\mathrm{a}} \\
\text { Subgroup analysis: } L \text { gasseri, L. casei, L. curvatus and L. plantarum } \\
\text { appeared more efficacious than placebo. }\end{array}$ \\
\hline $\begin{array}{l}\text { Dong et al, } \\
2019^{29}\end{array}$ & $\begin{array}{l}\text { NR } \\
599\end{array}$ & $\begin{array}{l}N R \\
8\end{array}$ & $3-24$ & $\begin{array}{l}81 \\
31\end{array}$ & $\begin{array}{l}\text { NR } \\
-0.34(-0.68,0.01)\end{array}$ & $\begin{array}{l}\text { WC: }-0.35(-0.8 \mathrm{I}, 0.1 \mathrm{I}) \\
\text { BFM: }-0.3 \mathrm{I}(-0.64,0.03) \\
\text { BF (\%): }-0.30(-0.58,-0.02)\end{array}$ \\
\hline $\begin{array}{l}\text { Dror et al, } \\
2017^{30}\end{array}$ & $\begin{array}{l}77 I \\
\text { NR }\end{array}$ & $\begin{array}{l}14 \\
8\end{array}$ & $3-26$ & $\begin{array}{l}N R \\
N R\end{array}$ & $\begin{array}{l}-0.54(-0.83,-0.25) \\
-0.43(-0.54,-0.33)\end{array}$ & \\
\hline $\begin{array}{l}\text { Hadi et al, } \\
2020^{31}\end{array}$ & $\begin{array}{l}1185 \\
1308\end{array}$ & $\begin{array}{l}19 \\
22\end{array}$ & $4-28$ & $\begin{array}{l}N R \\
N R\end{array}$ & $\begin{array}{l}-0.80(-1.56,-0.03) \\
-0.12(-0.40,0.16)\end{array}$ & $\begin{array}{l}\text { WC: }-2.07(-3.11,-1.03) \\
\text { BF (\%): } 0.02(-1.27,1.87) \\
\text { Subgroup analysis: larger effect if multi (vs single) species, duration } \\
<12 \text { (vs }>12) \text { wks. }\end{array}$ \\
\hline $\begin{array}{l}\text { John et al, } \\
2018^{32}\end{array}$ & $\begin{array}{l}790 \\
968\end{array}$ & $\begin{array}{l}13 \\
14\end{array}$ & $2-24$ & $\begin{array}{l}76 \\
30\end{array}$ & $\begin{array}{l}-0.65(-1.12,-0.18) \\
-0.33(-0.47,-0.18)\end{array}$ & $\begin{array}{l}\text { BFM: }-0.94(-1.17,-0.72) \\
\left.\text { Subgroup analysis: larger effect if dose }<10^{9} \text { (vs }>10^{9}\right) \text { CFU/d, duration } \\
>12(v s<12) \text { wks, single (vs multi) strain. } L \text { gasseri, } L \text {. casei, L. curvatus } \\
\text { and } L \text {. plantarum appeared more efficacious than placebo. }\end{array}$ \\
\hline $\begin{array}{l}\text { Koutnikova } \\
\text { et al, 201933 }\end{array}$ & $\begin{array}{l}3422 \\
4015\end{array}$ & $\begin{array}{l}58 \\
68\end{array}$ & $2-28$ & $\begin{array}{l}77 \\
28\end{array}$ & $\begin{array}{l}-0.39(-0.57,-0.31) \\
-0.33(-0.53,-0.12)\end{array}$ & $\begin{array}{l}\text { WC: }-1.01(-1.55,-0.48) \\
\text { BFM: }-0.62(-0.91,-0.34) \\
\text { Subgroup analysis: larger effect if used mixtures containing B. breve, } \\
\text { B. longum, Streptococcus salivarius subsp. thermophilus, L. acidophilus, } \\
\text { L. casei, L. delbrueckii. }\end{array}$ \\
\hline $\begin{array}{l}\text { Park et al } \\
2015^{34}\end{array}$ & $\begin{array}{l}196 \\
154\end{array}$ & $\begin{array}{l}4 \\
4\end{array}$ & $3-12$ & $\begin{array}{l}86 \\
32\end{array}$ & $\begin{array}{l}-1.77(-4.84, \text { I.29) } \\
0.77(-0.24, \text { I.78) }\end{array}$ & Population: included adolescents (NW, OW, OB) who gained BW. \\
\hline $\begin{array}{l}\text { Skonieczna- } \\
\text { Zydecka et al, } \\
2020^{35}\end{array}$ & $\begin{array}{l}1360 \\
1252\end{array}$ & $\begin{array}{l}25 \\
22\end{array}$ & $4-24$ & $\begin{array}{l}72 \\
27\end{array}$ & $\begin{array}{l}-0.09(-0.2,0.02) \\
-0.45(-0.69,-0.21)\end{array}$ & $\begin{array}{l}\text { WC: }-1.21(-2.27,-0.16) \\
\text { Population: healthy, } 66 \% \text { of RCTs included non-obese adults. } \\
\text { Regression analysis: direct association of BMI loss with duration and } \\
\text { baseline BMI. }\end{array}$ \\
\hline $\begin{array}{l}\text { Sun et al, } \\
2015^{36}\end{array}$ & $\begin{array}{l}\text { NR } \\
234\end{array}$ & $\begin{array}{l}N R \\
4\end{array}$ & $8-12$ & $\begin{array}{l}\text { NR } \\
28\end{array}$ & $\begin{array}{l}\text { NR } \\
-0.52(-0.81,-0.25)\end{array}$ & WC: $-2.11(-3.54,-0.68)$ \\
\hline $\begin{array}{l}\text { Suzumura } \\
\text { et al, } 2019^{37}\end{array}$ & $\begin{array}{l}1239 \\
895\end{array}$ & $\begin{array}{l}18 \\
15\end{array}$ & $3-24$ & $\begin{array}{l}89 \\
30\end{array}$ & $\begin{array}{l}-0.54(-1.09,0.01) \\
-0.19(-0.43,0.04)\end{array}$ & $\begin{array}{l}\text { WC: }-0.82(-1.43,-0.21) \\
\text { Subgroup analysis: larger effect if duration }>8(v s<8) \text { wks. }\end{array}$ \\
\hline
\end{tabular}

(Continued) 
Table I (Continued).

\begin{tabular}{|l|l|l|l|l|l|l|}
\hline $\begin{array}{l}\text { Study } \\
\text { Author, Year }\end{array}$ & $\begin{array}{l}\text { N } \\
\text { BW } \\
\text { BMI }\end{array}$ & $\begin{array}{l}\text { n } \\
\text { BW } \\
\text { BMI }\end{array}$ & $\begin{array}{l}\text { Dur } \\
\text { wks }\end{array}$ & $\begin{array}{l}\text { Base } \\
\text { BW } \\
\text { BMI }\end{array}$ & $\begin{array}{l}\text { Mean Difference } \\
\text { BW (95\% Cl) } \\
\text { BMI (95\% Cl) }\end{array}$ & $\begin{array}{l}\text { Additional Anthropometric Outcomes, Subgroup and } \\
\text { Regression Analysis, and Comments. }\end{array}$ \\
\hline $\begin{array}{l}\text { Wang et al, } \\
2019^{38}\end{array}$ & 641 & 10 & $8-24$ & $\begin{array}{l}81 \\
30\end{array}$ & $\begin{array}{l}-0.55(-0.91,-0.19) \\
-0.30(-0.43,-0.18)\end{array}$ & $\begin{array}{l}\text { WC: }-1.20(-2.21,-0.19) \\
\text { BFM: }-0.91(-1.19,-0.63) \\
\text { Subgroup analysis: larger effect if dose }>10^{10}\left(\mathrm{vs}<10^{10}\right) \text { CFU/d, single } \\
\text { (vs multi) strain, capsules or powder (vs food). }\end{array}$ \\
\hline $\begin{array}{l}\text { Zhang et al } \\
2015^{39}\end{array}$ & 1545 & $\begin{array}{l}21 \\
15\end{array}$ & $3-24$ & $\begin{array}{l}76 \\
28\end{array}$ & $\begin{array}{l}-0.59(-0.30,-0.87) \\
-0.49(-0.74,-0.24)\end{array}$ & $\begin{array}{l}\text { Subgroup analysis: larger effect if duration } \geq 8 \text { (vs <8) wks, multi (vs } \\
\text { single) strain, if only included RCTs for OW/OB. }\end{array}$ \\
\hline
\end{tabular}

Notes: All meta-analyses included RCTs of predominantly overweight or obese adults without or with comorbidities. The outcome values are mean difference (final minus baseline). Number of participants for data on WC and BF can differ from number of participants for analyses of BW and BMI. Baseline BW and BMI are mean values. The daily doses varied with the average between $10^{8}$ and $10^{10} \mathrm{CFU} /$ day. ${ }^{\mathrm{a}}$ The data are for capsules and powder, for food BW: NS; BMI: -0.33 ( $\left.-0.5 \mathrm{I},-0.16\right)$.

Abbreviations: B, Bifidobacterium; Base, baseline; BW (kg), body weight; BF, body fat; BFM (kg), body fat mass; $\mathrm{BMI}\left(\mathrm{kg} / \mathrm{m}^{2}\right)$, body mass index; CFU, colony-forming units; Cl, confidence interval; d, day; Dur, duration; L, Lactobacillus; N/n, number of participants/number of trials; NR, not reported; NS, not significant; NW, normal weight; OB, obese; OW, overweight; WC $(\mathrm{cm})$, waist circumference; wks, weeks.

of the bacterial species or contents of the supplements were not explicitly described. ${ }^{30}$ The outcomes for anthropometric measures varied but always included BMI, and 11 included BW (Table 1). The BW and BMI were not always the primary outcomes of the RCTs included in meta-analyses.

The methods for statistical analysis varied among reports. Some meta-analyses included comparisons of all groups using probiotics. ${ }^{33}$ Some included only the intervention with the highest dose and the smallest number of probiotic species from RCTs with multiple groups evaluating different doses or combinations of probiotics. ${ }^{30}$ The calculations of the effect measures differ to some extent. All meta-analyses calculated the effect measure based on the outcome mean value as baseline subtracted from final value to calculate mean change from baseline. All meta-analyses calculated the difference between the last preintervention measurement (baseline value) and the measurement at the end of the administration period (final value) for studies with more than two measurements during the follow-up. The formula for calculating mean difference required estimation of the standard error that was missing in some trials and was, therefore, estimated based on an assumption of the magnitude of correlation among the repeated outcome measurements (intrasubject correlation). A difference among meta-analyses was the intrasubject coefficient of variation since the trials did not explicitly report it. The chosen coefficient of variation differed from intermediate $(0.5)$ to high (0.9) and could influence the results of the statistical analysis (Table S3). Only a few meta-analyses explicitly stated that repeated statistical assessments were performed using different coefficients (low, intermediate, and high) to assure that the selected correlation coefficient did not influence the results. ${ }^{31,33}$ The majority of meta-analyses used the random effects statistical method, which allowed for heterogeneity in the results among studies and calculated estimates for the difference between probiotic and control. A fixed-effect model was used when heterogeneity among trials was regarded low. All meta-analyses included 95\% confidence interval (CI) for the results. The meta-analyses involving multiple outcomes and using trials with multiple results did not adjust for the outcome multiplicity. All meta-analyses assessed heterogeneity and reported moderate or high heterogeneity based on the $\mathrm{I}^{2}$ value defined as low $\left(\mathrm{I}^{2} 0-25 \%\right)$, intermediate $\left(\mathrm{I}^{2} 25-49 \%\right)$, moderate $\left(\mathrm{I}^{2} 50-74 \%\right)$, and high $\left(\mathrm{I}^{2} \geq 75 \%\right)$.

The prespecified subgroup analyses were performed by all but two studies. ${ }^{29,34}$ The choices of the subgroups differ, but majority included probiotic form (food vs supplement), the daily dose (usually more vs less than $10^{8}$ or $10^{10} \mathrm{CFU} /$ day), and the number of probiotic strains ( 1 vs $>1$ strain). Some included comparisons based on gender, separate effect for overweight, obese, and normal weight, and individual probiotic subspecies. ${ }^{33}$ The subgroups analysis from the report with the highest number of participants showed the largest effect size in overweight individuals. In contrast, the effect did not reach statistical significance in the obese and normal-weight subjects. ${ }^{33}$ The higher dose $\left(>10^{10} \mathrm{CFU} /\right.$ day) was associated with higher weight reduction only in one analysis, ${ }^{38}$ while the majority showed no effect. The duration did not substantially influence weight loss. However, a few reports showed positive, ${ }^{26,37,39}$ and some showed a negative association. ${ }^{27,31}$ Similarly, some ${ }^{28}$ but not the others ${ }^{26}$ 
showed that supplements in the form of capsules or powder were better than food form. Some $\mathrm{e}^{31,33,39}$ but not others ${ }^{32,38}$ reported that a combination of probiotics was more efficacious than a single species. The single species particularly helpful for weight loss appeared to be L. gasseri, L. casei, a combination of $L$. curvatus and L. plantarum ${ }^{28,32}$ as well as Bifidobacterium longum, L. delbrueckii, L. reuteri and L. rhamnosus. ${ }^{33}$ The effect appeared to be similar in men and women, ${ }^{33}$ but most meta-analyses did not evaluate the impact of gender.

All meta-analyses performed sensitivity evaluation by omitting a trial at a time to assess its effect on the results and some, ${ }^{33}$ but not all reassured robustness of the results by excluding trials conducted in one country since many of RCTs were from Iran. ${ }^{31}$ All meta-analyses performed quality assessments and the risk of publication bias according to the standardized procedures and reported low risk of bias. However, some meta-analyses reported that there were trials funded by companies with marked interests, researched by authors with vested financial interests, or lacked a priori sample size calculation and were regarded as having a high risk of other biases. ${ }^{26}$ Overall all meta-analyses were comprehensive in their approach to the methodology and results assessment.

\section{Discussion}

This review has focused on body weight change as the main outcome with probiotic use for obesity. This focus is justified since body weight is the most relevant clinical parameter measured for every patient in almost every clinical visit and is easily understood by the professionals and patients. The BMI has also been included as the main outcome as it is widely used for a definition of normal and abnormal (overweight, obese) weight and is utilized by various societies for guidelines on obesity management. ${ }^{1,4}$ The outcomes of waist circumference and body fat (assessed by bioelectrical impedance or dual x-ray absorptiometry) are impractical to measure outside of research. However, these have been added since these are important for mechanistic insights into weight reduction.

The majority of meta-analyses (11 of 14) showed a statistically significant reduction of body weight and/or BMI favoring probiotics compared to placebo. An average weight loss was $0.6 \mathrm{~kg}$ (calculated from data for 11 studies reporting weight loss), and the largest weight loss was $4.8 \mathrm{~kg}$ corresponding to $0.7 \%$ and $5.9 \%$ reductions in body weight, respectively, assuming baseline weight of $81 \mathrm{~kg}$ calculated as an average for 8 studies that reported baseline weight (Table 1). Reduction of body weight $3 \%$ to $5 \%$ is considered adequate for FDA approval of antiobesity medications since it results in clinically relevant improvement of metabolic and cardiovascular outcomes. ${ }^{11,40,41}$ The magnitude of weight reduction of less than $5 \%$ could be considered below the clinically relevant level. However, notwithstanding the small effect, probiotics use was safe and shown to be associated with improved health outcomes, at least when probiotics were incorporated in the food matrix. ${ }^{28}$ The meta-analysis of prospective cohort studies showed that yogurt intake was associated with decreased risk of T2D $(\sim 27 \%)$ and metabolic syndrome $(\sim 20 \%) .{ }^{28}$ Comparably, fermented milk was associated with reduced risk of combined stroke, ischemic heart disease, and cardiovascular mortality $(\sim 4 \%){ }^{28}$ Consequently, considering the overwhelming impact of obesity on the health of individuals and society, any simple and safe addition to the standard lifestyle weight loss program can be beneficial.

The differences among meta-analyses and specifically the negative results of three reports could be explained by the particulars of methodology, such as the choice of population, trials, comparison groups, and statistical approaches. ${ }^{29,34,37}$ The nonsignificant results in two reports could be explained by the small number of trials and participants suggesting that the meta-analyses could be underpowered. ${ }^{29,34}$ The other report had several inconsistencies. ${ }^{37}$ The report showed that waist circumference and not BW or BMI were significantly reduced, and the authors did not explain this discrepancy. There was a decrease of $\mathrm{BW}$ and $\mathrm{BMI}$ in probiotic compared to the control group, but the differences did not reach statistical significance $(\mathrm{p}=0.05$ and $=0.11$ for $\mathrm{BW}$ and BMI, respectively), suggesting that inclusion or exclusion of some trials or groups could have affected the statistical analysis.

The synbiotics were included in the review as both probiotics and synbiotics are expected to have comparable, but not the same effects, and some meta-analyses provided the effect of only synbiotics ${ }^{31}$ or combined effect of probiotics and synbiotics. ${ }^{27}$ Also, at times the designation of synbiotics varied. The meta-analysis with the largest number of RCTs and participants reported as dedicated to probiotics included synbiotics with fermentable fibers at a maximum dose of 1.5 $\mathrm{g} /$ day as the authors assumed that three times a day intake of $0.5 \mathrm{~g}$ fructo-oligosaccharides (FOS) would be insufficient to exert a significant prebiotic effect. ${ }^{33}$ FOS improve probiotics' survival in the gastrointestinal system similar to other 
prebiotic fibers; however, the dose of prebiotics providing relevant metabolic benefits is not well defined. The effects of synbiotics were similar to probiotics and showed modest reduction of body weight and BMI. Two reports with nonsignificant synbiotics' effects could be explained by the small number of participants and likely underpowered statistics since the effect size was small. ${ }^{32,37}$ The separate effect of prebiotics analyzed in two reports appeared lower than probiotics. $^{30,32}$ The prebiotics administration for obesity resulted in significant ${ }^{32}$ or non-significant ${ }^{30}$ decrease of $\sim 0.5 \mathrm{~kg}$ body weight.

The results for the subgroup analyses provided some mechanistic insight into probiotic effects. The subgroup analyses for the dosage showed inconsistent results suggesting that the effect could be J- or U-shaped, and that optimal dosing needed further investigation. The doses appeared to be chosen as available in traditional cultures for food and not based on rigorous preclinical studies. In addition, the probiotic effect is strain-specific, therefore each strain could have different optimal dosages. Similarly, the specific probiotic species and strains in food and supplements (capsules or other forms) seemed to be chosen based on traditional foods and not based on thorough investigations. The specificity of probiotic strain, dosage and chosen population could potentially introduce some bias into the outcomes and limit the generalizability of meta-analyses. The traditional foods known for centuries to benefit health contained multiple probiotics species and were not designed for weight loss. ${ }^{22,28,42,43}$ Indeed, the probiotics in starter cultures were associated with both weight gain and loss. For instance, L. acidophilus administration has been linked to weight gain, whereas L. gasseri, has been linked to weight loss in humans and animals. ${ }^{25}$ The conventional fermented dairy was associated with decreased risk of T2D $(\sim 27 \%)$ and cardiovascular disease $(\mathrm{CVD}, \sim 4 \%)^{28}$ while traditional fermented soybean (natto) was associated with reduced mortality from CVD $(\sim 25 \%)$ and stroke $(\sim 30 \%){ }^{42}$

The majority but not all fermented products contain probiotic bacteria, which could explain, at least in part, health benefits reported for these products. The traditional probiotics lactobacilli and bifidobacteria belong to the Generally Regarded as Safe (GRAS). Among Bacilli, an interesting example is Bacillus subtilis. B. subtilis is a probiotic present in the human gut, as well as such foods as kefir, natto, miso, tempeh, and fermented pickles. $^{42,44}$ The studies suggested that B. subtilis played a role in weight loss in RCT of kefir provided to overweight or obese premenopausal women. Compared to the control group, kefir intake resulted in a significant weight loss of $\sim 2.5 \mathrm{~kg}$ after 8 weeks. ${ }^{45}$ Bioengineered B. subtilis also demonstrated anti-obesity property by enhancing butyric acid production. The administration of bioengineered B. subtilis compared to wild B. subtilis resulted in reduced food intake and lower body weight in the animal model of obesity. ${ }^{46}$ B. subtilis was used for successful oral delivery of injectable anti-diabetic medication GLP-1 agonist. ${ }^{47}$ In a preclinical longevity study, B. subtilis colonized the nematode worm $C$. elegans gut and extended its lifespan. ${ }^{48}$ The primary mechanism was likely due to the downregulation of the insulin signaling system. This downregulation was also a critical factor in the healthy longevity of human centenarians. ${ }^{48}$ B. subtilis could also be a contributing factor in reduced mortality from CVD. ${ }^{42}$ Akkermansia muciniphila is another example of gut microbiota species with potential metabolic benefits in preclinical studies, ${ }^{49}$ including weight control and increased thermogenesis. ${ }^{50}$ The abundance of $A$. muciniphila in the gut is decreased in obesity and T2D. ${ }^{20,49}$ In the proof-ofconcept RCT (not included in any meta-analyses), daily oral supplementation with $10^{10} \mathrm{CFU} /$ day of either alive or pasteurized A. muciniphila to overweight or obese participants for 3 months was safe and improved cardiometabolic and inflammatory markers. ${ }^{49,51}$ The trial showed that intake of A. muciniphila compared to placebo was associated with an average weight loss of about $2 \mathrm{~kg}$ (up to $4 \mathrm{~kg}$ ). However, the differences did not reach significance likely due to small numbers of participants (about 10 in each of the three groups). ${ }^{49,51}$ Comparably, A. muciniphila appeared to be part of the mechanism of weight loss after bariatric surgery ${ }^{52}$ as well as anti-diabetic medications metformin $^{53}$ and GLP-1 agonists. ${ }^{54}$

There is vast preclinical basic and translational research suggesting multiple and complex mechanisms for probiotic actions in the obese state. Obesity is associated with gut microbial dysbiosis, which could alter the host's energy absorption and influence intestinal permeability, inflammation, immunity, and multiple other physiologic processes. ${ }^{14,15,19,20,23,49}$ Some examples of probiotic-related mechanisms include fermentation of non-digestible nutrients with or without increased energy utilization, ${ }^{14,15}$ reduced food intake, ${ }^{55}$ increased thermogenesis and energy dissipation, ${ }^{18,50}$ and involvement of physiologically active molecules such as gut hormones (eg, GLP-1, peptide YY, endocannabinoids, FGF21). ${ }^{20,56}$ Other mechanisms include 
short-chain fatty acids (SCFA), ${ }^{20,57}$ bile acids, neurotransmitters (serotonin, dopamine, gamma-aminobutyric acid), fasting-induced adipose factor, nervous system (enteric, vagus, and brain), and various receptors and their pathways (eg, G-protein coupled receptor 41). ${ }^{20}$ Interactions between human and microbiota genomes are suggested by heritability analysis $^{58}$ and the association found between blood group antigens and gut microbiota ecosystem. ${ }^{59}$ These data are congruent with previous results suggesting that gut microbiota can be a link between "nurture" and "nature," ie, environment and genetic predisposition. ${ }^{14,60}$

The obesity epidemic of the present time is unique in human evolution. Gut bacteria, including probiotics, evolved contemporaneously with the human host with evolutional pressure supporting cooperation (symbiosis) of bacteria and the human host. In addition to microbiota, symbiotic coexistence includes multiple gut species potentially possessing probiotic properties. Indeed, the genes of the microbiome represent about $93 \%$ of genes in the gut microorganisms. The rest is represented by viruses, including bacteriophages $(\sim 5.8 \%)$, archaea $(\sim 0.8 \%)$, fungi $(\sim 0.1 \%)$, and unidentified species $(\sim 0.3 \%))^{61}$ The "thrifty" gene hypothesis has postulated that evolutional pressure reinforced "thrifty" genes promoting the extraction of maximum calories (ie, energy) from food sources in both humans and gut microcosm to increase survivability when food (ie, energy) has been scarce (Figure 2). ${ }^{62-64}$ The gut microcosm, however, likely contains anti-"thrifty" anti-obesity genes yet to be identified. The formidable task of finding novel probiotics requires resources and innovative approaches. The concepts for consideration could include microbiota-host interactions (for example, according to blood type), ${ }^{65}$ adaptive thermogenesis, ${ }^{64}$ horizontal gene transfer, ${ }^{66,67}$ holobiont, ${ }^{66,68}$ and novel probiotics from unconventional sources. ${ }^{69}$ The armamentarium of probiotics could be expanded to include non-live bacteria, bacterial metabolites, bacteriophages, fungi, and biosynthetic probiotics designed to meet precision medicine criteria. $^{20,61,70}$

\section{Conclusion}

The review suggests that probiotics, despite small effects, could be a valuable addition to the armamentarium of obesity management. As part of the gut microbiota, probiotics appear to be a critical link in complex pathophysiological interaction networks involved in energy balance. The small effect of probiotics on weight reduction in randomized trials is significant yet could be deemed clinically irrelevant. However, notwithstanding the slight
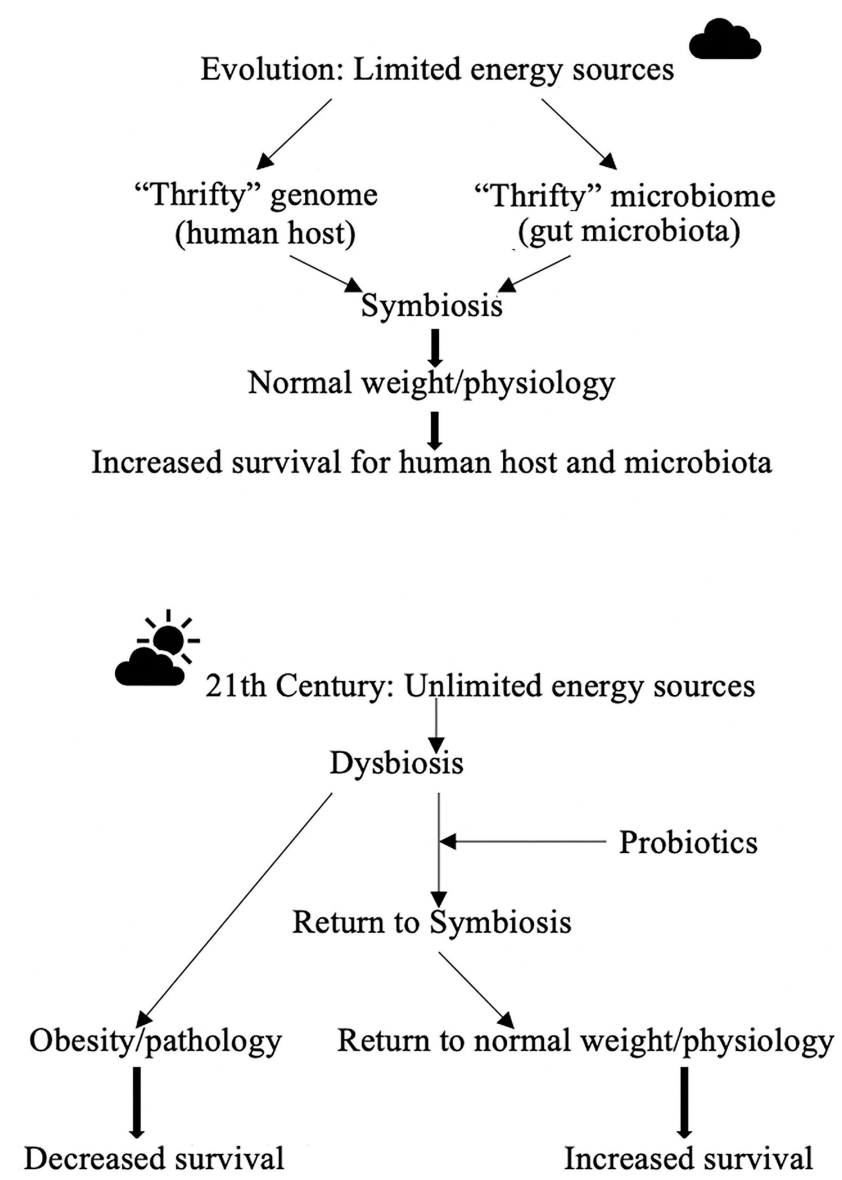

Figure 2 The potential role of probiotics in the fight against obesity.

decrease in body weight, probiotics' use is safe and shown to be associated with improved health outcomes. Further basic and translational research and clinical trials are required to elucidate mechanisms, and specific probiotic and patients' types for the best achievable precision medicine approach to the obesity epidemic.

\section{Disclosure}

The authors report no conflicts of interest in this work.

\section{References}

1. World Health Organization. Obesity and overweight; 2020. Available from: https://www.who.int/news-room/fact-sheets/detail/obesity-andoverweight. Accessed July 20, 2020.

2. NCD Risk Factor Collaboration (NCD-RisC). Trends in adult bodymass index in 200 countries from 1975 to 2014: a pooled analysis of 1698 population-based measurement studies with $19 \cdot 2$ million participants. Lancet. 2016;387(10026):1377-1396. doi:10.1016/S01406736(16)30054-X

3. World Health Organization. Body mass index-BMI. Available from: https://www.euro.who.int/en/health-topics/disease-prevention/nutri tion/a-healthy-lifestyle/body-mass-index-bmi. Accessed July 10, 2020 . 
4. Jastreboff AM, Kotz CM, Kahan S, Kelly AS, Heymsfield SB. Obesity as a disease: the obesity society 2018 position statement Obesity (Silver Spring). 2019;27(1):7-9. doi:10.1002/oby.22378

5. Romero-Corral A, Montori VM, Somers VK, et al. Association of bodyweight with total mortality and with cardiovascular events in coronary artery disease: a systematic review of cohort studies. Lancet. 2006;368(9536):666-678. doi:10.1016/S0140-6736(06) 69251-9

6. Chan DS, Vieira AR, Aune D, et al. Body mass index and survival in women with breast cancer-systematic literature review and meta-analysis of 82 follow-up studies. Ann Oncol. 2014;25 (10):1901-1914. doi:10.1093/annonc/mdu042

7. Doleman B, Mills KT, Lim S, Zelhart MD, Gagliardi G. Body mass index and colorectal cancer prognosis: a systematic review and meta-analysis. Tech Coloproctol. 2016;20(8):517-535. doi:10.1007/ s10151-016-1498-3

8. Flegal KM, Kit BK, Orpana H, Graubard BI. Association of all-cause mortality with overweight and obesity using standard body mass index categories: a systematic review and meta-analysis. JAMA. 2013;309(1):71-82. doi:10.1001/jama.2012.113905

9. Jensen MD, Ryan DH, Apovian CM, et al. 2013 AHA/ACC/TOS guideline for the management of overweight and obesity in adults: a report of the American College of Cardiology/American Heart Association Task Force on Practice Guidelines and The Obesity Society. Circulation. 2014;129(25 Suppl 2):S102-138. doi:10.1161/ 01.cir.0000437739.71477.ee

10. Gibson AA, Sainsbury A. Strategies to improve adherence to dietary weight loss interventions in research and real-world settings. Behav Sci (Basel). 2017;7(3).

11. Morrato EH, Allison DB. FDA approval of obesity drugs: a difference in risk-benefit perceptions. JAMA. 2012;308 (11):1097-1098. doi:10.1001/jama.2012.10007

12. Khera R, Murad MH, Chandar AK, et al. Association of pharmacological treatments for obesity with weight loss and adverse events: a systematic review and meta-analysis. JAMA. 2016;315 (22):2424-2434. doi:10.1001/jama.2016.7602

13. Hu Z, Sun J, Li R, et al. A comprehensive comparison of LRYGB and LSG in obese patients including the effects on QoL, comorbidities, weight loss, and complications: a systematic review and meta-analysis. Obes Surg. 2020;30(3):819-827. doi:10.1007/s11695019-04306-4

14. Turnbaugh PJ, Ley RE, Mahowald MA, Magrini V, Mardis ER, Gordon JI. An obesity-associated gut microbiome with increased capacity for energy harvest. Nature. 2006;444(7122):1027-1031 doi:10.1038/nature 05414

15. Jumpertz R, Le DS, Turnbaugh PJ, et al. Energy-balance studies reveal associations between gut microbes, caloric load, and nutrient absorption in humans. Am $J$ Clin Nutr. 2011;94(1):58-65. doi:10.3945/ajen.110.010132

16. Cani PD, Delzenne NM. The role of the gut microbiota in energy metabolism and metabolic disease. Curr Pharm Des. 2009;15 (13):1546-1558. doi:10.2174/138161209788168164

17. Gordon JI, Turnbaugh P, Inventors; Washington University in St Louis, assignee. Methods of promoting weight loss and associated arrays. US patent 20140128289A1. May 8, 2014.

18. Zhang C, He X, Sheng Y, et al. Allicin-induced host-gut microbe interactions improves energy homeostasis. FASEB $J$ 2020;00:1-17.

19. Cani PD, Lecourt E, Dewulf EM, et al. Gut microbiota fermentation of prebiotics increases satietogenic and incretin gut peptide production with consequences for appetite sensation and glucose response after a meal. Am J Clin Nutr. 2009;90(5):1236-1243. doi:10.3945/ ajcn.2009.28095

20. Rastelli M, Knauf C, Cani PD. Gut microbes and health: a focus on the mechanisms linking microbes, obesity, and related disorders. Obesity (Silver Spring). 2018;26(5):792-800. doi:10.1002/oby.22175
21. Hill C, Guarner F, Reid G, et al. Expert consensus document. The International Scientific Association for Probiotics and Prebiotics consensus statement on the scope and appropriate use of the term probiotic. Nat Rev Gastroenterol Hepatol. 2014;11(8):506-514. doi:10.1038/nrgastro.2014.66

22. Barengolts E, Smith ED, Reutrakul S, Tonucci L, Anothaisintawee T. The effect of probiotic yogurt on glycemic control in type 2 diabetes or obesity: a meta-analysis of nine randomized controlled trials. Nutrients. 2019;11(3).

23. Gibson GR, Hutkins R, Sanders ME, et al. Expert consensus document: the International Scientific Association for Probiotics and Prebiotics (ISAPP) consensus statement on the definition and scope of prebiotics. Nat Rev Gastroenterol Hepatol. 2017;14(8):491-502. doi:10.1038/nrgastro.2017.75

24. Shahbandeh M Dollar sales of probiotic ingredients in the United States from 2014 to 2024. Statista website; 2019. Available from: https://www.statista.com/statistics/492591/dollar-sales-probioticsupplements-united-states/. Accessed June 23, 2020.

25. Million M, Angelakis E, Paul M, Armougom F, Leibovici L, Raoult D. Comparative meta-analysis of the effect of Lactobacillus species on weight gain in humans and animals. Microb Pathog. 2012;53(2):100-108. doi:10.1016/j.micpath.2012.05.007

26. Borgeraas H, Johnson LK, Skattebu J, Hertel JK, Hjelmesaeth J. Effects of probiotics on body weight, body mass index, fat mass and fat percentage in subjects with overweight or obesity: a systematic review and meta-analysis of randomized controlled trials. Obes Rev. 2018;19(2):219-232. doi:10.1111/ obr. 12626

27. Cao S, Ryan PM, Salehisahlabadi A, et al. Effect of probiotic and synbiotic formulations on anthropometrics and adiponectin in overweight and obese participants: a systematic review and meta-analysis of randomized controlled trials. J King Saud Univ Science. 2020;32 (2):1738-1748. doi:10.1016/j.jksus.2020.01.011

28. Companys J, Pla-Pagà L, Calderón-Pérez L, et al. Fermented dairy products, probiotic supplementation, and cardiometabolic diseases: a systematic review and meta-analysis. Adv Nutr. 2020;11 (4):834-863. doi:10.1093/advances/nmaa030

29. Dong Y, Xu M, Chen L, Bhochhibhoya A. Probiotic foods and supplements interventions for metabolic syndromes: a systematic review and meta-analysis of recent clinical trials. Ann Nutr Metab. 2019;74(3):224-241. doi:10.1159/000499028

30. Dror T, Dickstein Y, Dubourg G, Paul M. Microbiota manipulation for weight change. Microb Pathog. 2017;106:146-161. doi:10.1016/j. micpath.2016.01.002

31. Hadi A, Alizadeh K, Hajianfar H, Mohammadi H, Miraghajani M. Efficacy of synbiotic supplementation in obesity treatment: a systematic review and meta-analysis of clinical trials. Crit Rev Food Sci Nutr. 2020;60(4):584-596. doi:10.1080/10408398. 2018.1545218

32. John GK, Wang L, Nanavati J, Twose C, Singh R, Mullin G. Dietary alteration of the gut microbiome and its impact on weight and fat mass: a systematic review and meta-analysis. Genes (Basel). 2018;9 (3).

33. Koutnikova H, Genser B, Monteiro-Sepulveda M, et al. Impact of bacterial probiotics on obesity, diabetes and non-alcoholic fatty liver disease related variables: a systematic review and meta-analysis of randomised controlled trials. BMJ Open. 2019;9(3):e017995. doi:10.1136/bmjopen-2017-017995

34. Park S, Bae JH. Probiotics for weight loss: a systematic review and meta-analysis. Nutr Res. 2015;35(7):566-575. doi:10.1016/j. nutres.2015.05.008

35. Skonieczna-Żydecka K, Kaźmierczak-Siedlecka K, Kaczmarczyk M, et al. The effect of probiotics and synbiotics on risk factors associated with cardiometabolic diseases in healthy people-a systematic review and meta-analysis with meta-regression of randomized controlled trials. J Clin Med. 2020;9(6). 
36. Sun J, Buys N. Effects of probiotics consumption on lowering lipids and CVD risk factors: a systematic review and meta-analysis of randomized controlled trials. Ann Med. 2015;47(6):430-440. doi:10.3109/07853890.2015.1071872

37. Suzumura EA, Bersch-Ferreira ÂC, Torreglosa CR, et al. Effects of oral supplementation with probiotics or synbiotics in overweight and obese adults: a systematic review and meta-analyses of randomized trials. Nutr Rev. 2019;77(6):430-450. doi:10.1093/nutrit/ nuz001

38. Wang Z-B, Xin -S-S, Ding L-N, et al. The potential role of probiotics in controlling overweight/obesity and associated metabolic parameters in adults: a systematic review and meta-analysis. Evid Based Complement Alternat Med. 2019;2019:3862971.

39. Zhang Q, Wu Y, Fei X. Effect of probiotics on body weight and body-mass index: a systematic review and meta-analysis of randomized, controlled trials. Int J Food Sci Nutr. 2015;67(5):571-580. doi:10.1080/09637486.2016.1181156

40. American Diabetes Association. 7. Obesity management for the treatment of type 2 diabetes: standards of medical care in diabetes-2018. Diabetes Care. 2018;41(Suppl1):S65-S72. doi:10.2337/dc18-S007

41. American Diabetes Association. 10. Cardiovascular disease and risk management: standards of medical care in diabetes-2020. Diabetes Care. 2020;43(Supp11):S111-S134. doi:10.2337/dc20-S010

42. Nagata $C$, Wada $K$, Tamura $T$, et al. Dietary soy and natto intake and cardiovascular disease mortality in Japanese adults: the Takayama study. Am J Clin Nutr. 2017;105(2):426-431. doi:10.3945/ ajcn.116.137281

43. Mozaffarian D. Dietary and policy priorities for cardiovascular disease, diabetes, and obesity: a comprehensive review. Circulation. 2016;133(2):187-225. doi:10.1161/CIRCULATIONAHA.115.018 585

44. Gao J, Gu F, Abdella NH, Ruan H, He G. Investigation on culturable microflora in Tibetan kefir grains from different areas of China. $J \quad$ Food Sci. 2012;77(8):M425-433. doi:10.1111/j.17503841.2012.02805.x

45. Fathi Y, Faghih S, Zibaeenezhad MJ, Tabatabaei SH. Kefir drink leads to a similar weight loss, compared with milk, in a dairy-rich non-energy-restricted diet in overweight or obese premenopausal women: a randomized controlled trial. Eur J Nutr. 2016;55 (1):295-304. doi:10.1007/s00394-015-0846-9

46. Bai L, Gao M, Cheng X, Kang G, Cao X, Huang H. Engineered butyrate-producing bacteria prevents high fat diet-induced obesity in mice. Microb Cell Fact. 2020;19(1):94. doi:10.1186/s12934-02001350-z

47. Kang M, Feng F, Ge Q, et al. Display of quintuple glucagon-like peptide 1 (28-36) nonapeptide on Bacillus subtilis spore for oral administration in the treatment of type 2 diabetes. J Appl Microbiol. 2020. doi:10.1111/jam.14729

48. Ayala FR, Bauman C, Cogliati S, Leñini C, Bartolini M, Grau R. Microbial flora, probiotics, Bacillus subtilis and the search for a long and healthy human longevity. Microb Cell. 2017;4(4):133-136. doi:10.15698/mic2017.04.569

49. Cani PD, de Vos WM. Next-generation beneficial microbes: the case of Akkermansia muciniphila. Front Microbiol. 2017;8:1765. doi:10.3389/fmicb.2017.01765

50. Shi X, Zhou X, Chu X, et al. Allicin improves metabolism in high-fat diet-induced obese mice by modulating the gut microbiota. Nutrients. 2019;11(12):2909. doi:10.3390/nu11122909

51. Depommier C, Everard A, Druart C, et al. Supplementation with Akkermansia muciniphila in overweight and obese human volunteers: a proof-of-concept exploratory study. Nat Med. 2019;25 (7):1096-1103.

52. Mabey JG, Chaston JM, Castro DG, Adams TD, Hunt SC, Davidson LE. Gut microbiota differs a decade after bariatric surgery relative to a nonsurgical comparison group [published online ahead of print, 2020 Apr 18]. Surg Obes Relat Dis. 2020.
53. Forslund K, Hildebrand F, Nielsen T, et al. Disentangling type 2 diabetes and metformin treatment signatures in the human gut microbiota [published correction appears in Nature. 2017 May 3;545(7652):116]. Nature. 2015;528(7581):262-266. doi:10.1038/ nature 15766

54. Remely M, Hippe B, Zanner J, Aumueller E, Brath H, Haslberger AG. Gut microbiota of obese, type 2 diabetic individuals is enriched in Faecalibacterium prausnitzii, Akkermansia muciniphila and Peptostreptococcus anaerobius after weight loss. Endocr Metab Immune Disord Drug Targets. 2016;16(2):99-106. doi:10.2174/1871530316666160831093813

55. Chagwedera DN, Ang QY, Bisanz JE, et al. Nutrient sensing in CD11c cells alters the gut microbiota to regulate food intake and body mass. Cell Metab. 2019;30(2):364-373.e367. doi:10.1016/j. cmet.2019.05.002

56. Kwon J, Kim B, Lee C, et al. Comprehensive amelioration of high-fat diet-induced metabolic dysfunctions through activation of the PGC$1 \alpha$ pathway by probiotics treatment in mice. PLoS One. 2020;15(2): e0228932. doi:10.1371/journal.pone.0228932

57. Byrne CS, Chambers ES, Morrison DJ, Frost G. The role of short chain fatty acids in appetite regulation and energy homeostasis. Int J Obes (Lond). 2015;39(9):1331-1338.

58. Goodrich JK, Davenport ER, Clark AG, Ley RE. The relationship between the human genome and microbiome comes into view. Аnпи Rev Genet. 2017;51:413-433. doi:10.1146/annurev-genet-110711-155532

59. Gampa A, Engen PA, Shobar R, Mutlu EA. Relationships between gastrointestinal microbiota and blood group antigens. Physiol Genomics. 2017;49(9):473-483. doi:10.1152/physiolgenomics.000 43.2017

60. Bäckhed F, Manchester JK, Semenkovich CF, Gordon JI. Mechanisms underlying the resistance to diet-induced obesity in germ-free mice. Proc Natl Acad Sci U S A. 2007;104(3):979-984. doi:10.1073/pnas.0605374104

61. Shkoporov AN, Hill C. Bacteriophages of the human gut: the "known unknown" of the microbiome. Cell Host Microbe. 2019;25 (2):195-209. doi:10.1016/j.chom.2019.01.017

62. Vatsiou AI, Bazin E, Gaggiotti OE. Changes in selective pressures associated with human population expansion may explain metabolic and immune related pathways enriched for signatures of positive selection. BMC Genomics. 2016;17:504. doi:10.1186/s12864-0162783-2

63. Higginson AD, McNamara JM, Houston AI. Fatness and fitness: exposing the logic of evolutionary explanations for obesity. Proc Biol Sci. 2016;283(1822):20152443.

64. Speakman JR. Evolutionary perspectives on the obesity epidemic: adaptive, maladaptive, and neutral viewpoints. Annu Rev Nutr. 2013;33:289-317. doi:10.1146/annurev-nutr-071811-150711

65. Kinoshita H, Wakahara N, Watanabe $M$, et al. Cell surface glyceraldehyde-3-phosphate dehydrogenase (GAPDH) of Lactobacillus plantarum LA 318 recognizes human A and B blood group antigens. Res Microbiol. 2008;159(9-10):685-691. doi:10.1016/j.resmic.2008.07.005

66. Rosenberg E, Zilber-Rosenberg I. Microbes drive evolution of animals and plants: the hologenome concept. mBio. 2016;7(2):e139501315. doi:10.1128/mBio.01395-15

67. Meehan CJ, Beiko RG. Lateral gene transfer of an $\mathrm{ABC}$ transporter complex between major constituents of the human gut microbiome. BMC Microbiol. 2012;12:248. doi:10.1186/1471-2180-12-248

68. Guerrero R, Margulis L, Berlanga M. Symbiogenesis: the holobiont as a unit of evolution. Int Microbiol. 2014;16(3):133-143.

69. Sornplang P, Piyadeatsoontorn S. Probiotic isolates from unconventional sources: a review. J Anim Sci Technol. 2016;58:26. doi:10.1186/s40781-016-0108-2

70. Piqué N, Berlanga M, Miñana-Galbis D. Health benefits of heat-killed (tyndallized) probiotics: an overview. Int $J$ Mol Sci. 2019;20(10):2534. doi:10.3390/ijms20102534 


\section{Publish your work in this journal}

Nutrition and Dietary Supplements is an international, peerreviewed, open access journal focusing on research into nutritional requirements in health and disease, impact on metabolism and the identification and optimal use of dietary strategies and supplements necessary for normal growth and development. The journal welcomes submitted papers covering original research, basic science, clinical \& epidemiological studies, reviews and evaluations, guidelines, expert opinion and commentary, case reports and extended reports. The manuscript management system is completely online and includes a very quick and fair peer-review system, which is all easy to use. Visit http://www.dovepress.com/testimonials.php to read real quotes from published authors. 